\title{
Risk of work addiction in academic physicians prevalence, determinants and impact on quality of life
}

\begin{abstract}
The prevalence of work addiction is constantly increasing worldwide, ranging from $8.3 \%$ to $30 \%$, especially among physicians. The aim of this study was to assess the prevalence and characteristics of Work Addiction among academic physicians and its influence on their mental and physical health. This is a cross-sectional survey conducted among the 293 academic physicians practicing in the teaching hospitals of the faculty of Medicine of Monastir in Tunisia. We used a self-administered questionnaire, with the «Work Addiction Risk Test » and the «SF-8 health survey». The participation rate was $24.3 \%, 24 \%$ were addicted to work and $56 \%$ were at high risk of addiction. WART score was significantly higher in single, females with medical history of depression or associated depression, poor physical and mental health and psychosomatic symptoms. It was significantly decreased with age, and seniority. Certain psychosocial factors increased WART score. Mental health score was significantly lower in single, females, assistant professor and increased with age, seniority and number of children. Academic physicians are at a high risk of developing work addiction. Preventive guided measures to reconcile family life and work as well as organizational strategies are recommended.
\end{abstract}

Keywords: Job stress, mental health, psychological well-being, work-life balance, addictive behaviors, physicians
Volume 5 Issue 5 - 202I

\author{
Irtyah Merchaoui,, ${ }^{1,2}$ Abir Gana, ${ }^{2}$ Samia \\ Machghoul, ${ }^{1,2}$ Ines Rassas, ${ }^{1,2}$ Marouen \\ Hayouni, ${ }^{1,2}$ Marwa Bouhoula, ${ }^{3}$ Neila Chaari, ${ }^{1,2}$ \\ Adnene Hanchi, ${ }^{1,2}$ Charfeddine Amri, ${ }^{1,2}$ \\ Mohamed Akrout ${ }^{1,2}$ \\ 'Department of Occupational Health and Ergonomics, Faculty of \\ Medicine of Monastir, University of Monastir, Tunisia \\ ${ }^{2}$ University of Monastir, Tunisia \\ ${ }^{3}$ Faculty of Medicine of Sousse, University of Sousse, Tunisia
}

Correspondence: Samia Machghoul, Department of Occupational Health and Ergonomics, Faculty of Medicine of Monastir, University of Monastir, Tunisia, Tel 21693444297, Email samiamachghoul@gmail.com

Received: September 09, 2021 | Published: October 26, 2021

\section{Introduction}

Work is necessary for most people and has many positive aspects such as providing financial stability due to a regular income, giving a sense of identity, a feeling of accomplishment and contributing to the society. Interestingly, despite the many benefits of work, some people seem to work excessively and compulsively. They are often called workaholics. This concept was created by Oats in 1968, who defined workaholism by analogy with alcoholism: Work (work or job) and alcoholism (alcoholism), to designate addiction to work. He, thus, compares the pathological relationship between a person and his work to alcohol dependence. ${ }^{1}$ In 1971, "confession of workaholic, the fact about work addiction", described workaholism as a "compulsion or uncontrollable need to work incessantly". ${ }^{2}$ Since then, research into workaholism has been steadily increasing and several screening instruments to identify workaholics have been developed. Many authors proposed different definitions. Machlowitz described somehow, in a positive way, the addiction to work and then considered workaholics as very efficient in their work and very satisfied with their lives. ${ }^{3}$ However, according to Anderson and Hetland, work addiction is defined as "being overly concerned about work, to be driven by an uncontrollable work motivation, and to put so much energy and effort into work that it impairs private relationships, spare-time activities, and/or health". ${ }^{4}$ On another hand, Spence and Robbins proposed a classification of workaholics based on a 'workaholic triad', consisting of work involvement, feeling driven to work and work enjoyment. ${ }^{5}$

All these definitions share a key feature: A tendency to work excessively hard in a compulsive way, involving loss of control over work and leading to several negative consequences, such as Burnout, depression, work-life imbalance and conflicts. ${ }^{6-8}$ Moreover, authors stated that some occupational characteristics may have an impact on work addiction, like excessive working time and psychological job demands. ${ }^{7}$ Concerning occupations at high risk of work addiction, several studies have shown that the most affected ones are those where employees occupy managerial positions, with a high job strain. ${ }^{9}$ Taking these results into account, physicians would have a favorable ground to develop a work addiction and several studies have been performed to assess work addiction in this particular population..$^{6,10,11}$ In literature, academics have also been prone to develop work addiction, probably because of long work hours and heavy work demands..$^{12-14}$

In the light of all literature data, we carried out this study about work addiction in academic physicians with the goal of:

I. Determining its prevalence

II. Looking for socio-demographic and occupational associated factors

III. Assessing its influence on their mental health.

\section{Methods}

\section{Study design and participants}

This is a cross-sectional study including all academic physicians from the teaching hospitals related to the Faculty of Medicine of Monastir in Tunisia. It lasted four months, from August to November 2018. Non-inclusion criteria were to be on secondment in foreign countries or in long-term sick leave. The survey was based on a self- administered questionnaire sent by mail to all academics on the faculty mailing list. We sent two reminders by mail to those who did not answer the first mail. Since medical studies in Tunisia are led in French, we chose to administer the questionnaire in French. 


\section{Outcome measures}

We used a self-administered questionnaire addressing six dimensions:

The first part concerned socio-demographic characteristic (age, gender, marital status, dependent children, lifestyle in accordance with tobacco and alcohol consumption, and medical history). The second section concerned occupational characteristics. The questionnaire specified different occupational determinants such as specialty, professional grade, occupational seniority, and perceived mental workload assessed by the participant through a subjective 4-grading scale. The third section evaluated psycho-social factors at work using eight questions inspired from the KARASEK scale. ${ }^{15}$ Karasek scale is a bi-dimensional tool based on the balance between two concepts: "the psychological job demands" related to the organizational environment strain and job strain. The second concept is "the decision latitude" taking into account the autonomy in the tasks organization and participation in decisions as well as the use of skills. Each question was rated apart. ${ }^{15}$ The fourth section explored psychosomatic disorders based on the International Classification of Diseases (ICD), 2016 version. Questions about psychosomatic disorders surrounded Somatoform autonomic dysfunction with:

Da Costa syndrome (palpitations, chest pain, fatigue),

Gastric neurosis (dyspepsia) and nausea.

Neurasthenia with dizziness, tension headaches and sleep disturbance.

Answers were self-rated on a 4 points Likert scale ranging from "never $/$ rarely=1" to "always $=4$ ". Assessing psychosomatic disorders was based on a score by adding all the response rates in each syndrome (Da costa syndrome, Gastric neurosis and nausea, and neurasthenia). Increasing Scores show a worse state in terms of symptoms frequency. The risk of work addiction in our study was assessed in the fifth section of the questionnaire by the work addiction risk test (WART). ${ }^{16}$ It is a self- administered questionnaire, developed by Robinson in 1999, through a US- student-population study. It measured the work dependency defined by Robinson as "overindulgence in and preoccupation with work, often to the exclusion and detriment of the workaholic's health, intimate relationships, and participation in child rearing". ${ }^{17}$ This test is widely used and consists of 25 questions based on reported symptoms to clinical psychologists specialized in workaholics treatment. Answers are self-rated on a 4 points Likert scale ranging from "never true $=1$ " to "always true $=4$ ". The test analyzes five dimensions: Compulsive tendencies, control, impaired communication/ self-absorption, Inability to delegate and self-worth. Three categories of results are possible with the WART: scores of 67-100 indicate high workaholic tendencies; scores of 57-66 indicate moderate workaholic tendencies and scores less than 57 are those of normal participants. The last section assessed the influence of work addiction on the quality of life by the SF-8 Health Survey. Healthrelated quality of life (HRQOL) has been an increasingly interesting concept in health services research in the past few decades. The Short Form-36 (SF-36) Health Survey, developed in the Medical Outcomes Studies has been a widely used instrument with 36 questions belonging to 8 sub-scales that, are then used to calculate 2 summary measure scores (physical component score PCS and mental component score MCS).

Since, the SF-36 is a time-consuming instrument, and the SF-8 explores the same 8 domains, we preferred to use the SF- 8 which is the shortest SF Health Survey consuming one to two minutes. ${ }^{18,19}$ The SF-8 is an 8-item-questionnaire, with a 4-week-recall-period. Four questions deal with the physical component of health with its specific dimensions: physical functioning, physical role, general health, and body pain. The remaining 4 questions focus on mental health component dealing with vitality, social functioning, emotional role, and mental health ${ }^{19}$ Each item has a 5 or 6-point response range. Physical (PCS) and mental (MCS) component measures were calculated using Quality Metric Health outcomes solutions software (License Number: QM037277). Higher summary PCS and MCS scores indicate better health. Scores above and below 50 are considered above and below the average.

\section{Statistical analysis}

We used the SPSS.21 version software for the statistical analysis. The univariate comparative study was conducted using ANOVA test for comparison of averages of over-2-groups variables and T-student test to establish the difference in averages between two groups. Verification of the normality of the two quantitative variables PCS and MCS was made. The threshold of significance has been set at 0.05 . Multi-varied analysis was performed using linear logistic regression multi- varied step-by-step to identify variables that are significantly related to work addiction, regardless of the other variables with a risk taken at 0.05 . The criterion for including independent variables in the regression model was a threshold of significance $<0.2$.

\section{Results}

\section{Socio-demographic and occupational characteristics:}

Our survey concerned 293 academic physicians working in three teaching hospitals related to the Faculty of Medicine of Monastir. Seventy-three participants answered the questionnaire. The participation rate was $24.32 \%$. As shown in table I, the mean age of participating physicians was $42.64 \pm 7.96$ years and the median seniority at work was 6 years $[\mathrm{QIR}=10]$. There were a slightly higher proportion of female participants with a sex ratio of 0.92 . Most of participants were married (87.7\%), with one to two children (52.1\%), non- smokers (89\%) and non-alcoholic (94.5\%). Participants had no medical history in $87.7 \%$ of the cases. Fifty-five of those with medical history had a medical background of depression. Regarding occupational characteristics, $42.5 \%$ of academic physicians were practicing a medical specialty, $11 \%$ of them a surgical one and $8.2 \%$ were fundamentalist physicians. Thirty nine per cent of the participants had a grade of assistants, $37 \%$ of associate professors, and the rest were professors. With regard to perceived mental workload, $95.9 \%$ of the participants had a high to moderate perception of theirs.

\section{WART score determinants}

The mean of work addiction test score was $65.05 \%$, a quarter of population study was addicted to work $(26 \%)$. It was significantly higher in females $(\mathrm{M}=68.65, \mathrm{SD}=11.92, \mathrm{p}=0.005)$ and in single participants $(\mathrm{M}=78.28, \mathrm{SD}=15.09, \mathrm{p}=0.003)$. In addition, the WART score significantly decreased with age $(p=0.04 ; \beta=-0.241)$, medical history of depression or associated depression $(\mathrm{M}=77.20$, $\mathrm{SD}=13.77, \mathrm{p}=0.034)$ and seniority $(\mathrm{p}=0.001 ; \beta=-0.387)$. With regard to psychosomatic symptoms, WART score was significantly higher in people with Da Costa syndrome $\left(\beta=0.501, \mathrm{p}=10^{-3}\right)$, gastric neurosis $\left(\beta=0.397, p=10^{-3}\right)$ and neurasthenia $\left(\beta=0.522, p=10^{-3}\right)$. Otherwise, no significant difference in the WART score according to the rest of variables (smoking or alcoholic habits, children number) was noticed (Table 1). 
Table I Distribution of mean WART score according to Socio-demographic and occupational characteristics

\begin{tabular}{|c|c|c|c|c|c|c|}
\hline \multicolumn{2}{|l|}{ Characteristics } & \multirow[t]{2}{*}{$\%$} & Mean WART score & \multicolumn{2}{|l|}{$\pm \mathrm{SD}$} & \multirow[t]{2}{*}{$\mathbf{P}$} \\
\hline Socio-demographic dat & & & & & & \\
\hline \multirow[t]{2}{*}{ Gender } & Male & 47.9 & 61.14 & 10.37 & & 0.005 \\
\hline & Female & 52.1 & 68.65 & 11.92 & & \\
\hline \multirow[t]{3}{*}{ Marital status } & Married & 87.7 & 63.9 & 10.6 & & 0.003 \\
\hline & Single & 9.6 & 78.28 & 15.09 & & \\
\hline & Divorced & 2.7 & 55.5 & 7.07 & & \\
\hline \multirow[t]{3}{*}{ Smoking } & No & 89 & 65.9 & 12.02 & & 0.2 \\
\hline & Yes & 5.5 & 57 & 7.78 & & \\
\hline & Former & 5.5 & 59.25 & 4.99 & & \\
\hline \multirow[t]{3}{*}{ Alcohol } & No & 94.5 & 65.24 & 11.99 & & 0.59 \\
\hline & Yes & 4.4 & 64.66 & 2.08 & & \\
\hline & Former & 1.4 & 53 & 0 & & \\
\hline \multirow[t]{3}{*}{ Medical History } & No & 87.7 & 64.5 & 11.26 & & 0.034 \\
\hline & Depression & 5.5 & 77.2 & 13.77 & & \\
\hline & Other & 6.8 & 58.75 & 9.7 & & \\
\hline \multicolumn{7}{|l|}{ Occupational data } \\
\hline \multirow[t]{3}{*}{ Speciality } & Medical & 58.9 & 67.96 & 7.84 & & 0.78 \\
\hline & Surgical & 26 & 64.75 & 12.31 & & \\
\hline & Fundamental & 15.1 & 65.5 & 7.84 & & \\
\hline \multicolumn{7}{|l|}{ Occupational grade } \\
\hline & Assistant & 39.7 & 66.34 & 10.42 & & 0.5 \\
\hline & Associate professor & 37 & 66.34 & 10.42 & & \\
\hline & Professor & 17 & 62.7 & 13.04 & & \\
\hline \multicolumn{7}{|c|}{ Perceived mental workload } \\
\hline & None & $\mathrm{I} .4$ & 65 & 65 & & 0.72 \\
\hline & Slight & 2.7 & 72.5 & 72.5 & & \\
\hline & Moderate & 32.9 & 63.41 & 63.41 & & \\
\hline & High & 63 & 65.58 & 65.58 & & \\
\hline \multirow[t]{4}{*}{ Continuous variables } & & $\beta$ & Mean & $\pm S D$ & $P$ & \\
\hline & Age & -0.24 & 42.64 & 7.96 & 0.04 & \\
\hline & Seniority & -0.35 & 8.73 & 7.63 & 0.001 & \\
\hline & Children number & -0.13 & 2.49 & 1.22 & 0.24 & \\
\hline
\end{tabular}

\section{Psycho-social factors at work}

With regard to psychosocial work conditions, $61.6 \%$ of the academic physicians found that they had to hurry up moderately to perform their work and $52.1 \%$ could rarely have a rest. One third of the study population $(32.8 \%$ ) had to frequently work extra hours, while $79.4 \%$ of them had, moderately to frequently, to finish their work at home. Sixty- two per cent of participants found that they were not working alone at all, and moderately benefit from colleagues' support in $46.5 \%$. astly, half of population study (52.1\%) did not find their work monotonous at all, and $68.4 \%$ considered their work organization rarely to moderately problematic. ANOVA tests showed that WART score was higher in people who had to frequently hurry up to do their work (75.66, $\mathrm{SD}=12.12, \mathrm{p}=0.01)$, those feeling lonely while working $(81.8, \mathrm{SD}=13.82, \mathrm{p}=0.009)$, and those frequently working extra hours $(71.8, \mathrm{SD}=12.11, \mathrm{p}=0.014)$.

\section{The physical and mental quality of life}

For statistical convenience we chose to combine, the two last response rates in the first item of physical health score in the SF8 health survey. Mean physical health score was $47.94 \pm 8.0$. Half of 
the study population $(53.4 \%)$ found that their health was generally good, $34.2 \%$ had no limited physical activity, $35.6 \%$ had very slight difficulty in performing daily activities and $31.5 \%$ did not feel pain at all. The WART score was higher in people who thought their health was very poor $(\mathrm{M}=74.33, \mathrm{SD}=9.07, \mathrm{p}=0.008)$ with difficulties to ensure daily activities at home or outside (71.71, $\mathrm{SD}=14.67, \mathrm{p}=0.01$ ) (Table 2). For statistical convenience we chose to combine, the two last response rates in the first, second and last items of mental health score in the SF8 health survey. The median mental health score was 42.54 [31.7-50.98]. Almost half the study population (47.9\%), had average energy intensity, $27.4 \%$ were a little bit disturbed by emotional problems, $31.5 \%$ had limited their social activities because of their physical states or emotional problems and $28.8 \%$ could no longer ensure their daily activities because of these problems. WART score was significantly higher for participants who had low or no energy at all $(\mathrm{M}=72.38, \mathrm{SD}=12.76, \mathrm{p}=0.017)$, limitation of social activity with family caused by emotional and physical problems $(\mathrm{M}=$ $70.85, \mathrm{SD}=12.22, \mathrm{p}=0.01$ ), disturbance due to emotional problems $(\mathrm{M}=70.85, \mathrm{SD}=15.97, \mathrm{p}=0.003)$, and difficulties to attend daily activities $(\mathrm{M}=74.91, \mathrm{SD}=12.49, \mathrm{p}=0.002)$. WART score seemed to significantly increase when physical and mental health decrease respectively $(\mathrm{p}=0.01, \beta=-0.3),\left(\mathrm{p}=10^{-3}, \beta=-0.43\right)$.

Table 2 Distribution of mean WART score according to SF8 Physical Health parameters

\begin{tabular}{|c|c|c|c|c|c|}
\hline Parameters & & $\%$ & Mean & \pm SD & $\mathbf{p}$ \\
\hline \multirow[t]{5}{*}{ Health in general } & Excellent & 2.7 & 57 & 2.82 & \multirow[t]{5}{*}{0.008} \\
\hline & Very good & II & 65.87 & 13.53 & \\
\hline & Good & 53.4 & 61 & 10.57 & \\
\hline & Fair & 24.7 & 71.27 & 10.86 & \\
\hline & Poor and Very poor & 8.2 & 74.33 & 9.07 & \\
\hline Activity limitation problems due to physical health & Never & 34.2 & 61.24 & 11.87 & \multirow[t]{4}{*}{0.125} \\
\hline \multirow[t]{3}{*}{ problems } & Rarely & 34.2 & 64.92 & 10.54 & \\
\hline & Sometimes & 23.3 & 69.41 & 13.19 & \\
\hline & Frequently & 8.2 & 69.16 & 8.03 & \\
\hline \multicolumn{6}{|c|}{ Difficulties to do daily activities at home or outside due to physical health problems } \\
\hline & Never & 34.2 & 61.4 & 12.24 & \multirow[t]{4}{*}{0.017} \\
\hline & Very rarely & 35.6 & 63.07 & 8.82 & \\
\hline & Rarely & 20.5 & 71.46 & 11.17 & \\
\hline & Frequently & 9.6 & 71.71 & 14.67 & \\
\hline \multicolumn{6}{|l|}{ Pain intensity } \\
\hline & Never & 31.5 & 61.43 & 11.83 & \multirow[t]{5}{*}{0.041} \\
\hline & Very light & 26 & 61.73 & 9.84 & \\
\hline & Light & 26 & 68.1 & 10.83 & \\
\hline & Moderate & 12.3 & 72.33 & 8.83 & \\
\hline & Sever & 4.1 & 72.66 & 22.85 & \\
\hline
\end{tabular}

\section{Multi variate analysis}

Multivariate regression showed an explicative model of increasing of WART score composed of low mental health score $(\mathrm{p}=0.01)$, hurrying up to finish work (0.030), working extra hours $(\mathrm{p}=0.008)$, loneliness at the work place $(\mathrm{p}=0.013)$ and a low seniority at work $(\mathrm{p}=0.023)($ Table 3$)$.

Table 3 Distribution of mean WART score according to SF8 Mental Health parameters

\begin{tabular}{llllll}
\hline Parameters & & $\%$ & Mean & ISD & P \\
\hline Energy intensity in the last 4 weeks & Huge & 4.1 & 57.66 & 2.3 & 0.017 \\
& A lot & 23.3 & 62.88 & 11.9 & \\
& Moderate & 47.9 & 62.97 & 10.25 \\
& Low or Nothing & 24.6 & 72.38 & 12.76 \\
\hline
\end{tabular}




\begin{tabular}{|c|c|c|c|c|c|}
\hline Parameters & & $\%$ & Mean & $\pm S D$ & $\mathbf{p}$ \\
\hline \multirow[t]{4}{*}{$\begin{array}{l}\text { Limitation of social activities with family caused by } \\
\text { emotional and physical problems }\end{array}$} & Never & 16.4 & 57.75 & 12.21 & 0.01 \\
\hline & Very rarely & 31.5 & 62.73 & 10.48 & \\
\hline & Rarely & 23.3 & 66.17 & 9.36 & \\
\hline & Frequently to no activities & 28.7 & 70.85 & 12.22 & \\
\hline \multirow[t]{5}{*}{$\begin{array}{l}\text { Disturbance due to emotional problems (anxiety, } \\
\text { depression and irritability) }\end{array}$} & Never & 23.3 & 58.52 & 13.08 & \\
\hline & Rarely & 27.4 & 62.5 & 7.74 & 0.003 \\
\hline & Moderately & 24.7 & 67.88 & 10.36 & \\
\hline & Frequently & 17.8 & 68.3 & 9.73 & \\
\hline & Extremely & 6.8 & 78.8 & 15.97 & \\
\hline \multirow[t]{4}{*}{$\begin{array}{l}\text { Impediment to attend daily activities (work, study) due to } \\
\text { emotional problems }\end{array}$} & Never & 28.8 & 59.33 & 11.26 & \\
\hline & Very rarely & 30.1 & 64.31 & 10.66 & 0.002 \\
\hline & Rarely & 24.7 & 66.05 & 9.1 & \\
\hline & Frequently and no activities & 16.4 & 74.91 & 12.49 & \\
\hline
\end{tabular}

\section{Mental health determinants}

\section{Socio-demographic and occupational characteristics}

The mental health score was significantly lower in female participants $\left(\mathrm{M}=37.19, \mathrm{SD}=12.51, \mathrm{p}=10^{-3}\right)$, single ones $(\mathrm{M}=31.37$, $\mathrm{SD}=15.70, \mathrm{p}=0.034)$ and at assistant grade $(\mathrm{M}=36.41, \mathrm{SD}=13.0 .2$, $\mathrm{p}=0.002)$. Additionally, mental health score increases with age $(p=0.001, \beta=0.39)$, seniority $\left(p=10^{-3}, \beta=0.423\right)$ and number of children in charge $(p=0.041, \beta=0.234)$. Otherwise, there was no significant variation of mental health score according to smoking, alcohol consumption, medical history, specialty and perceived mental workload (Table 4).

Table 4 Distribution of mean mental health score according to Socio- demographic and occupational characteristics

\begin{tabular}{|c|c|c|c|}
\hline Characteristics & MSC & $\pm \mathrm{SD}$ & $\mathbf{p}$ \\
\hline \multicolumn{4}{|l|}{ Socio-demographic data } \\
\hline Gender Male & 47.38 & 9.66 & 3-Oct \\
\hline Female & 37.19 & $|2.5|$ & \\
\hline Marital status Married & 42.98 & $1 \mathrm{I} .43$ & 0.034 \\
\hline Single & 31.37 & 15.7 & \\
\hline Divorced & 55.5 & 7.07 & \\
\hline Smoking No & 41.68 & 12.28 & 0.738 \\
\hline Yes & 44.72 & 12.39 & \\
\hline Former & 45.82 & 14.73 & \\
\hline Alcohol No & 42.21 & 12.53 & 0.86 \\
\hline Yes & 41.13 & 8.5 & \\
\hline Former & 53.5 & 7.52 & \\
\hline Medical History No & 42.09 & 12.32 & 0.168 \\
\hline Depression & 35.03 & 12.27 & \\
\hline Other & 50.63 & 7.3 & \\
\hline \multicolumn{4}{|l|}{ Occupational data } \\
\hline Speciality Medical & 40.18 & 12.29 & 0.438 \\
\hline Surgical & 45.03 & 12.85 & \\
\hline
\end{tabular}




\begin{tabular}{llll} 
Table Continued... & & & \\
\hline Characteristics & MSC & $\mathbf{\pm S D}$ & $\mathbf{p}$ \\
\hline Fundamental & 40.49 & 13.48 & \\
Occupational Assistant & 36.41 & 13.02 & 0.002 \\
Associate Professor & 44.17 & 10.97 & \\
Professor & 48.41 & 8.85 & \\
Perceived mental None & 51.54 & 6.45 & 0.341 \\
workload & & & \\
Slight & 30.49 & 2.25 & \\
Moderate & 40.18 & 10.71 & \\
High & 43.37 & 13.09 &
\end{tabular}

\begin{tabular}{lllll}
\hline Continuous variables & $\beta$ & Mean & $\mathbf{\pm S D}$ & $\mathbf{p}$ \\
\hline Age & 0.39 & 42.64 & 7.96 & $0.00 \mathrm{I}$ \\
Seniority & 0.423 & 8.73 & 7.63 & $3-\mathrm{Oct}$ \\
Children number & 0.234 & 2.49 & $\mathrm{I} .22$ & 0.04 \\
\hline
\end{tabular}

\section{Psycho-social factors at work}

The results show no significant difference in mental health score according to psychosocial factors at work.

\section{Psychosomatic disorders}

Mental health score was significantly decreased in people presenting with Dacosta syndrome $(\beta=-0.549, \mathrm{p}=10-3)$, gastric neurosis $(\beta=-0.361, p=0.002)$ and neurasthenia $(\beta=-0.476, p=10-3)$.

\section{Physical health and WART score}

Physical health score had no significant influence on mental health score, otherwise WART score had a significant impact on mental health score $(\mathrm{p}=10-3, \beta=-0.431)$.

\section{Multi variate analysis}

Multivariate regression showed an explicative model of high score of mental health composed of high occupational grade $(\mathrm{p}=0.04)$ and Low Da Costa syndrome score $(\mathrm{p}=10-3)$.

\section{Discussion}

\section{Work addiction prevalence}

This study showed that $26 \%$ of academic participants in the faculty of Medicine of Monastir were addicted to work and $56 \%$ of them were at high risk of work addiction. In the literature, work addiction rates vary from $8.3 \%$ in a nationally representative survey among employees in Norway to $30 \%$ of people in North America. ${ }^{14,20,21}$

\section{Determinants of WART score in academic physicians}

In the literature, many studies confirmed the sociodemographic impact on work addiction. ${ }^{22,23}$ The present study results showed that work addiction was significantly higher in single females. These results seem to be similar to those of literature supporting that women, might be more ambitious than men. In fact, in a study conducted in Norway in 2014, work addiction was significantly related to females who had better grade in complete education. ${ }^{21,22}$ The significant relationship between single status and Work addiction was explained in the literature by the harder work of workaholics.
This leads to spending much more effort and time into jobs than what it is required. In doing so, workaholics neglect their life outside their jobs, experience poor relational satisfaction and their partners leave them because of their lack of investment in the relationship. ${ }^{21,24,25,26}$ In contrary to the previous hypothesis, many authors proved that workaholic satisfaction with their personal relationship (with their spouse or partner) was minimally affected by Work addiction. ${ }^{27}$ Children number did not seem to have an impact on work addiction risk which is in accordance with Gülbeniz study and in conflict with Andreassen's. ${ }^{24,28}$ This study has been unable to demonstrate that smoking or alcoholic habits had significant relationship with work addiction in academic physicians. No mention of such relationship was found in the literature, even though psychologists generally use the same behavioral therapy methods. ${ }^{10}$ It may be explained by the different pathways to substance addiction and work addiction. ${ }^{29}$ Nevertheless, many studies converge to a high risk of substance and drug use in physicians. ${ }^{30}$ Another interesting finding was that, higher WART score was significantly associated with a medical history of depression. This could be explained by emotional exhaustion due to working over hours. ${ }^{31}$

Besides working over hours, women could be more exposed to emotional exhaustion, because of their higher tendency to multitask, deriving from their greater amount of responsibilities such as family duties, pick up children, cooking and cleaning. ${ }^{32}$ Seniority, as well as age, were negatively correlated to the WART score of academic physicians in the present study, which was in line with many studies. ${ }^{22,33}$ It was suggested that older people have a higher maturity, leading to a better ability to deal with job stress. They also have to deal with other responsibilities (exp: family) obliging them to adjust their work pattern by delegating work to younger ones. ${ }^{34,35}$ In this study, occupational data showed that seniority, as well as age, were negatively correlated to the WART score, which was in line with many studies. ${ }^{22,32}$ Assistant physicians in the faculty of Medicine of Monastir had higher WART score but without statistical relationship. In the Tunisian University Hospital's hierarchy, assistant professors have a higher tendency to working hard in this position for at least 4 years to upgrade to qualification of associate professor; this could explain the higher WART score in assistant physicians. These findings are not in line with literature, stating that professors are more prone 
to work addiction. They are, in fact, at the top of the hospital medical hierarchy, are asked to practice in clinics, but also undertake teaching and research and are usually department heads. ${ }^{10}$ As mentioned in results section, higher WART score was significantly associated with a frequent lone working, a frequent overtime work and the need to hurry up at work. These determinants had been previously proven by many studies. ${ }^{7,24}$

Referring to many studies, job demand leads to an excess of working time, which cause work addiction., ${ }^{7,24}$ Physician job is well known to expose to high demand, high level of responsibility, workload, emergency situations, making physicians very exposed to work addiction. ${ }^{11,36,37}$ The current study showed that work addiction was not related to job control (job performance, organization and master the use of machines and software).This result is reported by many previous studies..$^{33,38,39}$ Otherwise, Matsudaira K. reported a negative correlation of WART score with job control, while Andreassen C. reported a positive correlation between both variables. ${ }^{31,40}$ The current study, did not find any significant relation between colleague support and WART score, which is in line with some studies. ${ }^{40-42}$ Others found a negative correlation between social support and work addiction. ${ }^{10,31,33}$ In order to continue working, workaholics may create more work for themselves by making projects more complicated, by refusing to delegate work because of their high perfectionism and obsession with unattainable standards, and by spending a lot of time and efforts in unimportant activities. ${ }^{3,11}$ The present study showed a significant higher WART score in the different Somatoform dysfunction syndromes identified. In the literature, autonomic nervous system activity was frequently linked to workplace stressors. ${ }^{43}$ As for psychosomatic symptoms, a unique study was interested in establishing a link between them and different types of work addiction, it stated that psychosomatic symptoms were more related to dissatisfied workers than to real workaholics. ${ }^{44}$ Our study showed a negative correlation between mental, physical health scores and WART score. It means that, the more physical and mental health is impaired, the more work performance will lack. Worker productivity will be boost up by a daily compensatory effort at work resulting in a hard work which can lead to a risky work addiction situation..$^{55,46}$

\section{Mental health determinants in academic physicians}

The present study showed that mental health score increased with ageing. Previous studies revealed that general health declines with age, ${ }^{47,48}$ and specific mental health disorders, seem to be more prevalent in younger highly educated people..$^{49}$ Mental health score in our academic physician's population was significantly lower in single female participants. Many authors reported that women experience poorer mental well-being than men do and that it is negatively correlated to children's number. The latter result is in contradiction with ours (49) (50). A 26-European-country study showed evidence of lower prevalence of good mental wellbeing among women. It was attributed to women's, lower socioeconomic position, lesser participation in the public sphere as well as the double role of work and household..$^{51,52}$ Others explain the mental wellbeing alteration in women and the higher prevalence of mental health disorder, like anxiety and depression by biological and especially hormonal differences between genders leading to a differential sensitivity to some special events like reproduction, housing and martial relation. ${ }^{53,54}$ Some authors, report the single status as a risk factor of developing mental health problems which is in accordance with our results. ${ }^{49,55}$ As for occupational risk factors of mental health problems, many studies proved that medical occupational field workers and especially physicians were at risk of poor mental health..$^{56-58}$ Regarding grade, our study showed a significant lower mental health score in assistant professors; it can be explained by the frustration they suffer from when dealing with an important job strain and weak decision latitude. That makes them more vulnerable to developing mental illnesses. ${ }^{59,60}$

As for occupational seniority, mental health score significantly increased with it in our academics. Similar results were reported by Ailing et al who proved that working in the same occupation over fifteen years, was a protective factor against a poor mental health. A possible explanation for this might be that ageing workers, with great occupational seniority, can use their work and social experience to cope with stressful working conditions, and thereby can sustain a good mental health. ${ }^{58}$ Otherwise, our results showed that there was no significant variation of mental health quality score according to smoking, alcohol consumption, medical history, specialty and perceived workload. Regarding the influence of psychosocial factors at work on mental health, our study results show no significant variation. Otherwise, many studies have shown a significant implication of psychosocial factors at work in the emergence of mental health problems. ${ }^{61}$ Authors explain the association between working long hours with elevated levels of strain and ill health by the hard workers insufficient opportunity of recovery from their excessive efforts. ${ }^{62,63}$ In literature, mental health problems are positively associated with job demand and negatively associated with job resources..$^{64,65,60}$ Schaufeli and colleague, have Suggested that workaholics work in unfavorable psychosocial job environments that might inhibit growth, development, and learning and can consequently worsen mental health. ${ }^{7}$

Furthermore, our results revealed that the different psychosomatic symptoms had a significant correlation on the decrease of mental health score, which is in line with some studies. ${ }^{66,67}$ In fact, psychosomatic symptoms might be important signals of mental health problems and should be seriously taken into account, as psychosomatic problems in daily living. They can be both indicative and predictive of mental distress ${ }^{68}$ Concerning the influence of physical health and WART score on mental health, physical health score had no influence on mental health score, while WART score was responsible in a significant impairment of the latter. Many previous studies had shown that better physical health can improve mental health, this relation was mediated by physical activity (low stress and anxiety, more life satisfaction. . $9,70,71^{-1}$ Some authors suggest that impaired physical health makes people more vulnerable to common mental disorders. ${ }^{50}$ In literature, many studies had confirmed the negative effect of workaholism on worker well-being. In fact, workaholic had a worse state of general health, more somatic symptoms, higher levels of anxiety/insomnia, social dysfunction and symptoms of depression..$^{72,31,13}$ Thomas Ng. et al support the hypothesis that poorer physical and mental health among workaholics is consequent to the carelessness of priority of protective behavior such as leisure activities and exercise. ${ }^{73}$

\section{Study limits}

The major limitation of this study is the low participation rate, which makes the findings less generalisable to general population. It was consequent to the short period of survey and the small number of mail reminders. Another weakness deserves to be cited. This current study has only examined a small homogenous sample of highly educated, experienced, academic physicians from one faculty of Medicine. Other academics from other disciplines deserve to be included as well as academic physicians from other faculties. Thirdly, the personality types according to 'The big five model' should have been explored with other variables in the questionnaire. ${ }^{74}$ 


\section{Conclusion}

Work addiction is a behavioral addiction that can lead to reduced life quality, job dissatisfaction and impaired productivity. It is an increasingly common concept that can affect different occupational sectors and doctors do not seem to be spared. The current study results suggest that work addiction in academic physicians is worsened by an impaired mental health, a shorter occupational seniority, an important job demand in terms of rapidity, overtime work and loneliness at work. On another side, academic physician mental health quality was better in senior academics and participants with rare psychosomatic symptoms. Consequently, many preventive and therapeutic measures should be taken. The primary prevention is based on adapted programs for reconciling family life and work in order to avoid considering work as the only mean of self- esteem. It is also generally admitted that organizational strategies and facilities availability, in the teaching hospital as well as in the faculty, alleviate the job strain and avoid the risk to be addicted. Future studies about work addiction should focus on the personality type so we can differentiate between the real work addict and the hard worker. At last, the creation of a special multidisciplinary committee responsible for mental suffering at work can be a good way to formalize and apply preventive strategies for screening and managing workaholic.

\section{Acknowledgments}

The authors would like to thank all the participants in our study. The authors declare that they have no funding sources.

\section{Statement of ethics}

All participants provided their online informed consent.

\section{Data accessibility statement}

The datasets used and/or analyzed during the current study are available from the corresponding author on reasonable request.

\section{Conflicts of interest}

The authors declare no conflict of interest.

\section{References}

1. Oates WE. On being a "workaholic”. Pastoral Psychology. 1968.

2. Oates, Wayne E. Confessions of a workaholic; the facts about work addiction. 1971.

3. Machlowitz M. Workaholics: living with them, working with them. 1981.

4. Schou Andreassen C, Hetland J, Pallesen S. Psychometric assessment of workaholism measures. Raphael Snir and Prof Itzhak Harpaz D, éditeur. Journal of Managerial Psychology. 2013;29(1):7-24.

5. Spence JT, Robbins AS. Workaholism: Definition, measurement, and preliminary results. Journal of personality assessment. 1992

6. Schaufeli WB, Bakker AB, Heijden FMMA van der, et al. Workaholism, burnout and well- being among junior doctors: The mediating role of role conflict. Work Stress. 2009;23(2):155-72.

7. Schaufeli WB, Taris TW, Rhenen WV. Workaholism, Burnout, and Work Engagement: Three of a Kind or Three Different Kinds of Employee Wellbeing? Appl Psychol. 2008;57(2):173-203.

8. Taris TW, Van Beek I, Schaufeli WB. Demographic and Occupationa Correlates of Workaholism. Psychol Rep. 2012;110(2):547-54.

9. Clark MA, W. SG, S. MJ, Zimmerman L. Workaholism among Leaders Implications for Their Own and Their Followers' Well-Being. In: The Role of Leadership in Occupational Stress. Emerald Group Publishing Limited; 2016. p. 1-31.
10. Rezvani A, Bouju G, Keriven-Dessomme B, et al. Workaholism: are physicians at risk? Occup Med. 2014;64(6):410-416.

11. Mazzetti G, Biolcati R, Guglielmi D. Individual Characteristics Influencing Physicians' Perceptions of Job Demands and Control: The Role of Affectivity, Work Engagement and Workaholism. Int J Environ Res Public Health. 2016;13(6):567.

12. Azevedo WF de, Mathias LA da ST, Azevedo WF de, et al. Work addiction and quality of life: a study with physicians. Einstein São Paulo. 2017;15(2):130-135.

13. Bartczak M, Ogińska-Bulik N. Workaholism and Mental Health Among Polish Academic Workers. Int J Occup Saf Ergon. 2012;18(1):3-13.

14. Hogan V, Hogan M, Hodgins M. A study of workaholism in Irish academics. Occup Med. 2016;66(6):460-465.

15. Ponge R. Philippe Zawieja, Franck Guarnieri (dir.), Dictionnaire des risques psychosociaux. Paris, Seuil, 2014. Trav Empl. 2014;(140):67-70.

16. Robinson BE. The Work Addiction Risk Test: Development of a Tentative Measure of Workaholism. Percept Mot Skills. 1999;88(1):199-210.

17. Sharp R. Work Addiction Risk Test. Occup Med. 2016;66(4):341-342.

18. Lang L, Zhang L, Zhang P, et al. Evaluating the reliability and validity of SF-8 with a large representative sample of urban Chinese. Health Qual Life Outcomes. 2018;16.

19. Tomás JM, Galiana L, Fernández I. The SF-8 Spanish Version for HealthRelated Quality of Life Assessment: Psychometric Study with IRT and CFA Models. Span J Psychol. 2018;21:E1.

20. van Wijhe C, Peeters M, Schaufeli W. Irrational Beliefs at Work and Their Implications for Workaholism. J Occup Rehabil. 2013;23(3):336-346.

21. Andreassen CS, Griffiths MD, Hetland J, et al. The Prevalence of Workaholism: A Survey Study in a Nationally Representative Sample of Norwegian Employees. PLOS ONE. 2014;9(8):e102446.

22. Kunecka D, Hundert M. The extent of workaholism in a group of polish nurses. Int J Health Plann Manage. 2019;34(1):e194-202.

23. Burke RJ, Berge Matthiesen S, Pallesen S. Workaholism, organizationa life and well-being of Norwegian nursing staff. Career Dev Int. 2006;11(5):463-477.

24. Andreassen CS, Griffiths MD, Sinha R, et al. The Relationships between Workaholism and Symptoms of Psychiatric Disorders: A Large-Scale Cross-Sectional Study. PLoS ONE. 2016;11(5).

25. Hauk M, Chodkiewicz J. The role of general and occupational stress in the relationship between workaholism and work-family/family-work conflicts. Int J Occup Med Environ Health. 2013;26(3):383-393.

26. Hakanen J, Peeters M. How Do Work Engagement, Workaholism, and the Work-to-Family Interface Affect Each Other? A 7-Year Follow-Up Study. J Occup Environ Med. 2015;57(6):601-609.

27. McMillan LHW, O'Driscoll MP, Brady EC. The impact of workaholism on personal relationships. Br J Guid Couns. 2004;32(2):171-186.

28. Akduman G, Hatipoğlu Z, Yüksekbilgili Z. Work Addiction as Related to Number of Children. 2015;2:129-137.

29. Sussman S. Workaholism: A Review. J Addict Res Ther. 2012;Suppl 6(1)

30. Marshall EJ. Doctors' health and fitness to practise: treating addicted doctors. Occup Med. 2008;58(5):334-340.

31. Matsudaira K, Shimazu A, Fujii T, et al. Workaholism as a Risk Factor for Depressive Mood, Disabling Back Pain, and Sickness Absence. PLoS ONE. 2013;8(9).

32. Beiler-May A, Williamson RL, Clark MA, et al. Gender Bias in the Measurement of Workaholism. J Pers Assess. 2017;99(1):104-110.

33. Andreassen CS, Bakker AB, Bjorvatn B. Working Conditions and Individual Differences Are Weakly Associated with Workaholism: A 2-3Year Prospective Study of Shift-Working Nurses. Front Psychol. 2017;8. 
34. Nzinga J, McKnight J, Jepkosgei J, et al. Exploring the space for task shifting to support nursing on neonatal wards in Kenyan public hospitals. Hum Resour Health. 2019;17(1):18.

35. Riisgaard H, Søndergaard J, Munch M, et al. Associations between degrees of task delegation and job satisfaction of general practitioners and their staff: a cross-sectional study. BMC Health Serv Res. 2017;17.

36. Tanner G, Bamberg E, Kozak A, et al. Hospital physicians' work stressors in different medical specialities: a statistical group comparison. J Occup Med Toxicol Lond Engl. 2015;10.

37. Schaufeli WB, Bakker AB, van der Heijden FMMA, et al. Workaholism among medical residents: It is the combination of working excessively and compulsively that counts. Int J Stress Manag. 2009;16(4):249-272.

38. Shimazu A, Schaufeli WB, Kubota K, et al. Do Workaholism and Work Engagement Predict Employee Well-being and Performance in Opposite Directions? Ind Health. 2012;50(4):316-21.

39. Guglielmi D, Simbula S, Schaufeli WB, et al. Self-efficacy and workaholism as initiators of the job demands-resources model. Career Dev Int. 2012;17(4):375-389.

40. Andreassen CS, Pallesen S, Torsheim T. Workaholism as a Mediator between Work-Related Stressors and Health Outcomes. Int J Environ Res Public Health. 2018;15(1).

41. Shimazu A, De Jonge J, Kubota K, et al. Psychological Detachment from Work during Off-job Time: Predictive Role of Work and Non-work Factors in Japanese Employees. Ind Health. 2014;52(2):141-146.

42. Choi Y. The Differences Between Work Engagement and Workaholism, and Organizational Outcomes: An Integrative Model. Soc Behav Personal Int J. 2013;41.

43. Jarczok MN, Jarczok M, Mauss D, Koenig J, et al. Autonomic nervous system activity and workplace stressors--a systematic review. Neurosci Biobehav Rev. 2013;37(8):1810-1823.

44. Burke RJ. Workaholism in organizations: psychological and physical well-being consequences. Stress Med. 2000;16(1):11-16.

45. Falco A, Girardi D, Kravina L, et al. The mediating role of psychophysic strain in the relationship between workaholism, job performance, and sickness absence: a longitudinal study. J Occup Environ Med. 2013;55(11):1255-1261.

46. Binnewies C, Sonnentag S, Mojza EJ. Daily performance at work: Feeling recovered in the morning as a predictor of day-level job performance. $J$ Organ Behav. 2009;30(1):67-93.

47. Cacchione PZ, Pike KM, Spaeth-Rublee B, et al. Health and Aging Policy Fellows: Dementia and Mental Health Policy to Improve Lives of Older Adults. J Am Geriatr Soc. 2018;66(S1):S53-S57.

48. Liu YB, Xue LL, Xue HP, et al. Health Literacy, Physical and Mental Health, and Activities of Daily Living Among Older Chinese Adults in Nursing Homes. Asia Pac J Public Health. 2018;30(6):592-599.

49. Amroussia N, Gustafsson PE, Mosquera PA. Explaining mental health inequalities in Northern Sweden: a decomposition analysis. Glob Health Action. 2017;10(1):1305814.

50. Krishnakumar A, Narine L, Roopnarine JL. Sociodemographic, psychosocial and physical health correlates of common mental disorder symptoms among mothers in Trinidad and Tobago: Examining ethnic variations. Int J Psychol. 2018;53(4):304-312.

51. Dreger S, Gerlinger T, Bolte G. Gender inequalities in mental wellbeing in 26 European countries: do welfare regimes matter? Eur J Public Health. 2016;26(5):872-876.

52. Bilodeau J, Marchand A, Demers A. Work, family, work-family conflict and psychological distress: A revisited look at the gendered vulnerability pathways. Stress Health. 2020;36(1):75-87.
53. Kiely KM, Brady B, Byles J. Gender, mental health and ageing. Maturitas. 2019;129:76-84.

54. Franks WLM, Crozier KE, Penhale BLM. Women's mental health during pregnancy: A participatory qualitative study. Women Birth. 2017;30(4):e179-1e87.

55. Kong KA, Choi HY, Kim SI. Mental health among single and partnered parents in South Korea. PLOS ONE. 2017;12(8):e0182943.

56. Mihailescu M, Neiterman E. A scoping review of the literature on the current mental health status of physicians and physicians-in-training in North America. BMC Public Health. 2019;19(1):1363.

57. Pereira-Lima K, Loureiro SR. Burnout, anxiety, depression, and social skills in medical residents. Psychol Health Med. 2015;20(3):353-362.

58. Fu A, Liu B, Jiang Y, et al. A Mental Health Survey of Different Ethnic and Occupational Groups in Xinjiang, China. Int J Environ Res Public Health. 2017;14(1):46.

59. Cohen D, Winstanley SJ, Greene G. Understanding doctors' attitudes towards self-disclosure of mental ill health. Occup Med. 2016;66(5):383-389.

60. Urbina-Garcia A. What do we know about university academics' mental health? A systematic literature review. Stress Health. 2020;36(5):563-585.

61. Roelen CAM, van Hoffen MFA, Waage S, et al. Psychosocial work environment and mental health-related long-term sickness absence among nurses. Int Arch Occup Environ Health. 2018;91(2):195-203.

62. Sato K, Kuroda S, Owan H. Mental health effects of long work hours, night and weekend work, and short rest periods. Soc Sci Med. 2020;246:112774.

63. Afonso P, Fonseca M, Pires JF. Impact of working hours on sleep and mental health. Occup Med. 2017;67(5):377-382.

64. Stansfeld S, Candy B. Psychosocial work environment and mental health - a meta-analytic review. Scand $J$ Work Environ Health. 2006;32(6):443-462.

65. Midje HH, Nafstad IT, Syse J, et al. Workaholism and Mental Health Problems Among Municipal Middle Managers in Norway. J Occup Environ Med. 2014;56(10):1042-1051.

66. Glozah FN, Pevalin DJ. Association between psychosomatic health symptoms and common mental illness in Ghanaian adolescents: Age and gender as potential moderators. J Health Psychol. 2017;22(11):1376-1386.

67. Svedberg P, Eriksson M, Boman E. Associations between scores of psychosomatic health symptoms and health-related quality of life in children and adolescents. Health Qual Life Outcomes. 2013;11(1):176.

68. Freyler A, Köhegyi Z, Köteles F, et al. Modern health worries, subjective somatic symptoms, somatosensory amplification, and health anxiety in adolescents. J Health Psychol. 2013;18(6):773-7781.

69. Ohrnberger J, Fichera E, Sutton M. The relationship between physical and mental health: A mediation analysis. Soc Sci Med. 2017;195:42-49.

70. Gerber M, Pühse U. Review Article: Do exercise and fitness protect against stress-induced health complaints? A review of the literature. Scand J Public Health. 2009;37(8):801-819.

71. Bowe AK, Owens M, Codd MB, et al. Physical activity and mental health in an Irish population. Ir J Med Sci. 2019;188(2):625-631.

72. Shimazu A, Schaufeli WB. Is Workaholism Good or Bad for Employee Well-being? The Distinctiveness of Workaholism and Work Engagement among Japanese Employees. Ind Health. 2009;47(5):495-502.

73. Ng TWH, Sorensen KL, Feldman DC. Dimensions, antecedents, and consequences of workaholism: a conceptual integration and extension. $J$ Organ Behav. 2007;28(1):111-136.

74. Elowe J. Boulomanie: entre illusion et addiction. L'Encéphale. 2010;36(4):285-293. 